\title{
Cutaneous metastasis of colon adenocarcinoma: case report and review of the literature
}

\author{
Metástasis cutânea de adenocarcinoma colorretal: relato de caso \\ e revisão da literatura
}

Ioannis Nesseris ${ }^{1}$

Ilias Ditsos ${ }^{4}$

\author{
Charalambos Tsamakis ${ }^{2}$ \\ Eleftheria Christofidou ${ }^{5}$
}

\author{
Stamatis Gregoriou ${ }^{3}$ \\ Dimitris Rigopoulos ${ }^{6}$
}

\begin{abstract}
Skin metastases from colorectal carcinoma are rare and signal advanced disease. We present a case of an 80-year-old male with a large skin metastatic focus in the lower abdomen, a year after resection of a colonic adenocarcinoma. The patient had already finished receiving his first cycle of chemotherapy shortly before the discovery of the abdominal nodules and at the same period a chest X-ray, revealed shadows at the base of the right lung. Keywords: Adenocarcinoma; Neoplasm Metastasis; Skin neoplasms

Resumo: Metástases cutáneas provocadas por carcinoma colorretal são raras e sinalizam doença avançada. Apresentamos o caso de um homem de 80 anos com um grande foco metastático na pele do baixo abdômen, um ano após a ressecção de um adenocarcinoma do cólon. O paciente já havia acabado de receber o seu primeiro ciclo de quimioterapia pouco antes da descoberta dos nódulos abdominais e, no mesmo período, um raio- $X$ do tórax revelou sombras na base do pulmão direito.

Palavras-chave: Adenocarcinoma; Metástase neoplásica; Neoplasias cutâneas
\end{abstract}

\section{INTRODUCTION}

Skin metastases from colorectal carcinoma are rare and usually appear within two years after resection of the primary tumor. They typically signify widespread disease with poor prognosis. ${ }^{1,2}$ We present a case of an 80-year- old male with a large skin metastatic focus on the lower abdomen about a year after resection of a colonic adenocarcinoma.

\section{CASE REPORT}

An 80-year-old male presented at the outpatient clinic with a growing mass on the abdominal skin. (Figure 1). On clinical examination, a diffuse erythematous multinodular cauliflower-like lesion was evident, with satellite nodules located in the periumbili- cal and lower abdominal region. A zone of pink indurated erythema surrounded the central mass. A large scar was evident at the base of the mass suggesting previous abdominal surgery and possible initial eruption of the mass on the scarred site.

The patient had a history of colorectal adenocarcinoma. He was initially hospitalized for hematochezia 12 months previously. Colonoscopy showed a cauliflower-like mass at the right flexure of the colon, and various polyps. A right hemi-colectomy was performed and histopathology showed a mucinous adenocarcinoma, with vascular and lymphatic emboli. No distant metastasis was found. The adenocarcinoma was staged T3N1M0. A month later, the

\footnotetext{
Received on 14.01.2013.

Approved by the Advisory Board and accepted for publication on 20.02.2013.

* Work performed at the University of Athens Medical School, 2nd Dermatology Department, Attikon Hospital - Athens, Greece.

Conflict of interest: None

Financial funding: None

MD - Consultant, Pathology Department, Andreas Sygros Hospital - Athens, Greece.

MD - Senior Registrar, Attikon Hospital - Xaidari, Greece.

MD, PhD - Consultant, University of Athens Medical School, Dermatology Department, Attikon Hospital - Xaidari, Greece

MD - Dermatologist Venereologist, Fellow of the University of Athens Medical School, Dermatology Department, Attikon Hospital - Xaidari, Greece.

MD, PhD - Consultant, Pathology Department, Andreas Sygros Hospital - Athens, Greece.

AdHoc - AdHoc University of Athens, Department of Dermatology, Attikon Hospital - Xaidari, Greece.

(C)2013 by Anais Brasileiros de Dermatologia
} 
patient started receiving 5-fluorouracil-based adjuvant chemotherapy for six months. Four months after the first cycle of chemotherapy was concluded, a chest X-ray was performed. This revealed shadows at the base of the right lung. It was interpreted by the radiologists as a possible spread of the known adenocarcinoma.

We obtained a biopsy specimen of the abdominal lesion. On microscopic examination the dermis was infiltrated by a number of adenomatous glands with obvious atypia and mucinous content, which was consistent with a metastatic focus of the known mucinous colon adenocarcinoma (Figures 2 and 3).

Computerized axial tomography was unremarkable with the exception of the right lung shadow.

The patient is currently receiving his second cycle of chemotherapy and is in good overall condition.

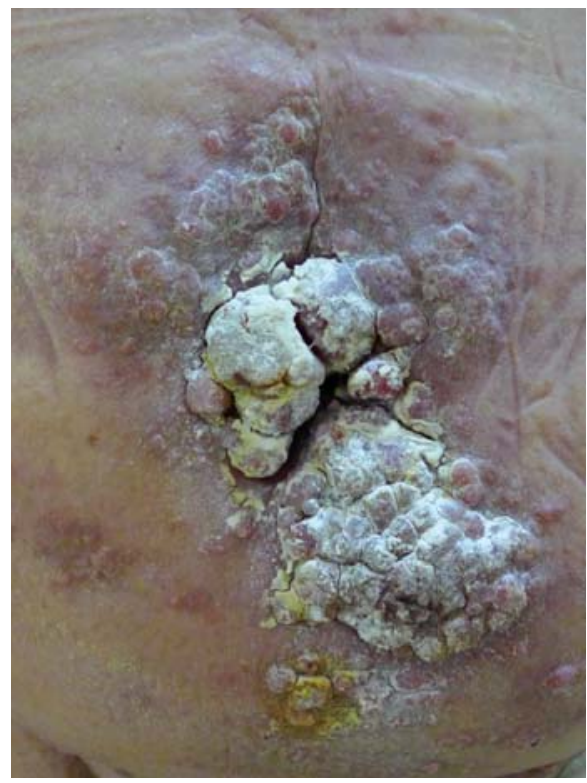

FIGURE 1:

Multinodular lesion with satellite nodules on an erythematous base, measuring $19 \times 8.5 \times 2 \mathrm{~cm}$, on the abdominal skin.

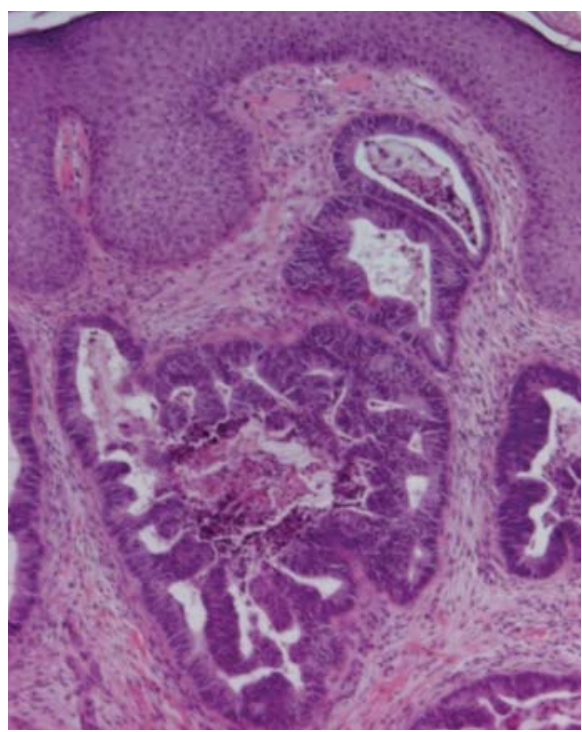

FIGURE 2:

Histologic section of metastatic foci of the skin: irregular branching and cribriform glands with pseudostratified columnar epithelium; luminal mucus and inflammatory cells. H\&E x40

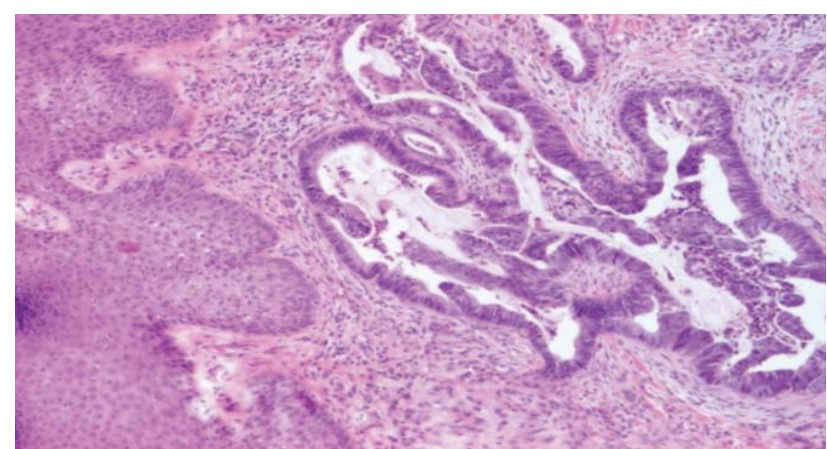

FIGURE 3: Histologic section of metastatic foci of the skin: irregular branching and cribriform glands with pseudostratified columnar epithelium; luminal mucus and inflammatory cells. H\&E x40

\section{DISCUSSION}

Skin metastasis of cancer is rare, occurring in $0.7-5 \%$ of cancer patients. Increased frequency of up to $9 \%$ has been reported in selected patient series., ${ }^{3,4}$ Cutaneous metastasis among patients with metastatic cancer has been reported to be $10.4 \% .^{5}$

Breast cancer is the most common primary cancer with cutaneous metastasis, with an incidence of $24 \%$ according to a meta-analysis by Krathen et al. ${ }^{6}$ Lung cancer, colorectal cancer, renal cancer, ovarian cancer and bladder cancer all have similar rates of cutaneous metastasis ranging between $3.4-4.0 \% .^{6}$

Frequency of skin metastasis of colorectal carcinoma has been reported to be $2.3-6 \% .^{3,4}$ Interestingly, according to a 2008 Taiwanese study, the rate of cutaneous metastasis from colorectal carcinoma is $0.81 \%$, suggesting a remarkable difference in frequencies between Caucasian and Taiwanese patient populations. ${ }^{7}$

Skin metastases from colorectal adenocarcinoma generally occur within the first two years after resection of the primary tumor and often present simultaneously with metastases to the liver, peritoneum and lung. ${ }^{1}$ The most frequent site of cutaneous metastasis of colonic cancer is the abdominal skin, often on surgical incision scars. This is not exclusive to the ad hoc surgical incision scar, but also to preexisting unrelated operative scars. ${ }^{5}$ Other cutaneous sites in order of decreasing frequency are the pelvis, back, chest, upper extremities, head and neck. ${ }^{8}$ Uncommon reported sites of skin metastasis of colorectal cancer include scalp, face, eyelids, tip of the nose, nostril, forearm, genitalia, ankle and big toe. ${ }^{1,2,4}$ Umbilical metastasis (Sister Mary Joseph's nodule) is a recurrent finding., ${ }^{4,5}$

Cutaneous metastasis may occur through lymphogenous spread, intravascular dissemination, direct extension of tumor and surgical implantation. ${ }^{9}$ Wong et al added the spread along embryonal remnants such as the urachus to the aforementioned mechanisms. ${ }^{8}$ 
Metastatic carcinoma can assume a variety of morphologic appearances. ${ }^{9}$ It usually presents as violaceous to flesh-colored, firm, freely mobile, painless nodules, single or multiple. It can sometimes mimic epidermal cysts, neurofibromas, lipomas, cicatricial morphea-like plaques, lymphoma and alopecia. ${ }^{4}$ More rarely it can mimic infection, and present as a zone of pink to deep red or purplish red indurated erythema with a well-demarcated border, a condition termed inflammatory metastatic carcinoma or carcinoma erysipelatoides. ${ }^{8}$ Data regarding the macroscopic appearance of cutaneous metastatic lesions of colonic carcinoma, is scarce in the medical literature. In a large series by Lookingbill et al, all the remote metastases were described as nodular. ${ }^{5}$

Histologic features of metastatic lesions in general resemble those of the primary tumor. However, metastases are frequently more anaplastic. With the exception of renal cell carcinoma, metastases do not always permit identification of the primary tumor. ${ }^{5}$ Skin metastases can be broadly classified as adenocarcinoma, squamous carcinoma, undifferentiated carcinoma and other types. ${ }^{5}$ Most skin metastases from large intestine tumors are well differentiated, often mucin-secreting adenocarcinomas. They usually have a nodular configuration and are located in the dermis, with subsequent spread to the epidermis and subcutaneous tissue. ${ }^{2}$

\section{REFERENCES}

1. Verardino GC, Silva RS, Obadia DL, Gripp AC, Alves Mde F. Rare cutaneous metastasis from a probable basaloid carcinoma of the colon mimicking pyogenic granuIoma. An Bras Dermatol. 2011:86:537-40.

2. Lookingbill DP, Spangler N, Sexton FM. Skin involvement as the presenting sign of internal carcinoma. A retrospective study of 7316 cancer patients. J Am Acad Dermatol. 1990;22:19-26.

3. Pereira WA, Humaire CR, Silva CS, Fernandes LH. Sister Mary Joseph's nodule: a sign of internal malignancy. An Bras Dermatol. 2011;86:S118-20.

4. Lookingbill DP, Spangler N, Helm KF. Cutaneous metastases in patients with metastatic carcinoma: a retrospective study of 4020 patients. J Am Acad Dermatol. 1993;29:228-36

5. Krathen RA, Orengo IF, Rosen T. Cutaneous metastasis: A meta-analysis of data. South Med J. 2003:96:164-166.

6. Hu SC, Chen GS, Wu CS, Chai CY, Chen WT, Lan CC. Rates of cutaneous metastases from different internal malignancies: Experience from a Taiwanese medical center. J Am Acad Dermatol. 2009;60:379-87

7. Wong NS, Chang BM, Toh HC, Koo WH. Inflammatory metastatic carcinoma of the colon: A case report and review of the literature. Tumori 2004;90:253-255.

8. Kauffman $\mathrm{CL}$, Sina B. Metastatic inflammatory carcinoma of the rectum: tumour spread by three routes. Am J Dermatopathol. 1997;19:528-32.
Identification of skin metastasis from an internal malignancy is considered a poor prognostic sign, as it reflects widespread disease. ${ }^{2}$ Survival after diagnosis of cutaneous metastasis ranges from 1 to 34 months. The average survival of patients after diagnosis of skin metastasis from colon cancer is, according to Lookingbill et al., 18 months. ${ }^{5}$

Wide local excision of the cutaneous metastatic lesion is the preferred treatment option in isolated lesions. In cases of extensive cutaneous metastases treatment is only palliative. Extensive tumor resection of those neoplasms can result in giant abdominal wall defects. Reconstruction of the abdominal wall is not easy for an average general surgeon or even a plastic surgeon. Most reports describe reconstructing giant abdominal wall defects by using synthetic mesh implants, autologous tissue graft, or a combination of the two. ${ }^{9}$ No clear guidelines exist for an optimum chemotherapeutic regimen. Established chemotherapy treatments include 5-fluorouracil, capecitabine, irinotecan, oxaliplatin and cisplatin. Combinations of irinotecan to bolus 5-FU, oxaliplatin to infusional 5FU and leucovorin (LV) (FOLFOX) or infusional 5FU/LV with irinotecan (FOLFIRI) has increased survival to over 20 months. Treating patients sequentially with FOLFIRI followed by FOLFOX, or with FOLFOX followed by FOLFIRI, has increased the median survival times to 21.5 months and 20.6 months respectively. ${ }^{10} \square$

9. Gu Y, Tang R, Gong DQ, Qian YL. Reconstruction of the abdominal wall by using a combination of the human acellular dermal matrix implant and an interpositional omentum flap after extensive tumor resection in patients with abdominal wall neoplasm: a preliminary result. World J Gastroenterol. 2008;14:752-7.

10. Tournigand C, André T, Achille E, Lledo G, Flesh M, Mery-Mignard D, et al. FOLFI$\mathrm{RI}$ followed by FOLFOX6 or the reverse sequence in advanced colorectal cancer: a randomized GERCOR study. J Clin Oncol. 2004;22:229-37.
MAILING ADDRESS:
Dimitris Rigopoulos
University of Athens Medical school, Dermatology Department, Attikon Hospital
1 Rimini Str,
12462 - Athens - Greece
E-mail: stamgreg@yahoo.gr

How to cite this article: Nesseris I, Tsamakis C, Gregoriou S, Ditsos I, Christofidou E, Rigopoulos D. Cutaneous metastasis of colon adenocarcinoma: case report and review of the literature. An Bras Dermatol. 2013;88(6 Suppl 1):S56-8. 